\title{
Fatal Dilema de Abel Botelho \\ e a teatralização do conflito interior da personagem
}

Anabela Morais Brás;

Cândido Oliveira Martins ${ }^{1}$

RESUMO: Num primeiro momento, pretende-se situar o romance Fatal Dilema (1907) no ideário naturalista que preside à série romanesca "Patologia Social" e apresentar a redação simultânea da peça teatral homónima (1893), ainda inédita. Num segundo momento, procura-se demonstrar a natureza eminentemente teatral do romance, a partir de uma reflexão em torno de momentos narrativos que comprovam que a intriga é arquitetada sobre o conflito (interior) das personagens, tal como o é na tragédia e no teatro clássicos.

ABSTRACT: In this text, we intended to reflect about Abel Botelho's novel Fatal Dilema, the fourth volume of the romanesque series "Patologia Social". We will try to show that this novel has a theatrical fabula arquitecture, mainly by focusing the characters' thoughts and secret feelings. This characteristic also reveals the existence of a relation between the novel and the homonymous unknown drama Fatal Dilemma (1983).

PALAVRAS-CHAVE: Abel Botelho; conflito interior; Fatal Dilema; naturalismo; teatralização da narrativa.

KEYWORDS: Abel Botelho; inner conflict; Fatal Dilema; naturalism; dramatization of the narrative.

\section{I}

Em 1891, há cerca de 120 anos, era publicado o romance O Barão de Lavos, o primeiro volume da série romanesca "Patologia Social" de Abel Botelho (1855-1917), de que o Fatal Dilema (1907) é o quarto romance. Consabidamente, a crítica literária e a história da literatura são bastante permeáveis à repetição de certos lugares-comuns, que proliferam mais ou menos acriticamente. Esse é o caso de Abel Botelho, frequentemente apresentado sob a etiqueta de naturalista

1 Licenciada pela Univ. Nova de Lisboa, mestranda e investigadora a desenvolver um trabalho de investigação sobre o drama inédito Fatal Dilemma (1893), de Abel Botelho (email: anabelamoraisbras@ gmail.com); Professor Titular de Teoria da Literatura na Univ. Católica Portuguesa, Braga, Portugal (email: martins.candido@gmail.com). 
tardio, com mais ou menos variações a este topos crítico de pós-naturalista ou "rótulo de naturalista" epigonal, como a de discutir o grau de ortodoxia desse programa naturalista (cf. Serrão, 1978; Simões, 1987). Neste âmbito, poucos são os estudiosos que, nos últimos anos, têm contribuído de modo decisivo para a avaliação crítica de estereótipos como esse, através do aprofundado estudo da obra deste autor, à luz de informados critérios histórico-periodológicos.

No fim de século XIX, quando já se manifestavam novas tendências estéticas no sistema literário português, os cinco volumes do referido ciclo romanesco "Patologia Social" 2 visavam consumar as orientações programáticas expostas na "explicação- - - programa" do "Prólogo da Segunda Edição" de O Barão de Lavos (1898) - a saber, proceder à análise da sociedade coeva, a partir da detida dissecação das suas anormalidades e patologias individuais:

Por três modos diferentes se pode manifestar e exercitar a actividade humana, objectiva e psíquica. Dentro de três fórmulas fundamentais se encerra todo o campo de acção da nossa individualidade, do nosso ipseísmo, do nosso modo de ser social e íntimo. De três sortes de faculdades, apenas, depende a solução do problema da nossa vida: faculdades de sentimento, de pensamento e de acção.

Quando o valor de todas as três é igual, ou pelo menos equivalente, no modalismo orgânico de um indivíduo, este realiza o tipo fisiológico banal, sem interesse para o meu ponto de vista. O predomínio, porém, de qualquer dessas faculdades, no doseamento dum carácter, origina desequilíbrios, aberrações e anormalismos patológicos, os quais fazem o objecto dos estudos dessa minha série de romances.

O Barão de Lavos, e O Livro de Alda pretendem ser a análise de dois exemplares humanos tiranizados pela diátese das

\footnotetext{
2 A publicação de ciclos, séries ou cenas romanescas constitui uma opção muito frequente do variado programa realista-naturalista no campo da escrita ficcional - de Eça de Queirós a Émile Zola -, como forma de abarcar a diversidade do painel da vida contemporânea, tal como teorizado entre nós por Júlio Lourenço Pinto (1996), em Estética Naturalista (1884).
} 
faculdades afectivas, - o caso mais comum. Nos romances seguintes, procurarei dar o translado pitoresco de caracteres em que, ainda essa e as duas outras ordens de faculdades predominem.

Eis em duas palavras a génese, o pensamento inicial da série dos meus romances sobre "Patologia Social". (Botelho, 1898: VII-VIII).

Como decorre destas considerações programáticas - imbuídas de um cientificismo positivista, centrado na fisiologia e nas patologias -, e à imagem de outros ficcionistas da segunda metade de Oitocentos, o projeto estéticoliterário do autor passava pela construção de um amplo universo romanesco que incidisse sobre indivíduos que se destacassem por revelarem “desequilíbrios, aberrações e anormalismos patológicos", provocados pela falta de comedimento na gestão das "faculdades de sentimento, de pensamento e de acção". Por isso, centrado numa fauna "latrinária" (para usarmos a expressão de Joel Serrão) e tendendo para o romance de tese, o empreendimento do romancista consiste numa assumida e minuciosa análise naturalista, fundada genericamente no "método experimental", primeiramente anunciado no campo literário por Émile Zola, em Le Roman Experimental [1880] e amplamente cultivado por muitos dos seus seguidores europeus.

Entretanto, anote-se ainda que Fatal Dilema é também um romance da assumida preferência do seu autor, como confessa em carta particular, datada de 1 de agosto de 1916, endereçada à esposa, D. ${ }^{a}$ Virgínia de Alcântara Pinto Guedes de Vasconcelos: “Entretive agora o tempo a reler a tradução espanhola de Fatal Dilema, que saiu bastante fiel. Lido agora assim em língua diferente, pareceu-me de outro autor, e agradou-me bastante. Parece-me que já te disse, é dos meus livros aquele de que mais gosto." ${ }^{3}$ Naturalmente, este elemento peritextual não pode ser descurado.

\footnotetext{
3 Carta inédita de 1 de Agosto de 1916 (Biblioteca da Academia de Ciências de Lisboa).
} 
Ao mesmo tempo, e bem mais relevante para o tópico que escolhemos analisar, impõe-se uma segunda reflexão - Fatal Dilema é uma daquelas criações romanescas em que as tradicionais classificações genológicas têm de ser repensadas ou matizadas. Tratando-se de um romance, o modo narrativo escolhido está contaminado por uma forte e visível teatralidade. A dimensão dramática das cenas e episódios, bem como o retrato completo das figuras, assim o parece exigir.

Por outras palavras, o ponto de vista narrativo adotado por Abel Botelho em Fatal Dilema valoriza, de modo manifesto, a análise do conflito interior da personagem. Neste aspecto como em outros (por ex., no recurso a um certo fatalismo, a lances melodramáticos, mas igualmente a uma linguagem vernácula), a escrita romanesca de Abel Botelho, congenialmente teatral, apresenta algumas "reminiscências camilianas" (Jesus, 1995: 723) ${ }^{4}$. Recorde-se, a título de curiosidade que o admirado escritor de S. Miguel de Seide tinha falecido precisamente no ano anterior (1890).

Entre outros elementos configuradores, a teatralização intrínseca da narrativa de Abel Botelho, em Fatal Dilema, decorre sobretudo da centralidade do conflito (ágon, na terminologia clássica da tragédia grega) num amplo sentido - conflito entre personagens, conflito interior ou conflito de consciência, nomeadamente nas figuras mais relevantes - protagonista, antagonista, deuteragonista. Com um perfil e atuação mais ou menos dilemáticos, objeto de uma análise a vários níveis (falas, atos e pensamentos), a personagem romanesca em toda a sua "ilusão realista" - e sem deixar de ser elemento central da narrativa de Abel Botelho - constitui-se como um espelho privilegiado para compreender os complexos mecanismos da alma humana e da sua actuação em sociedade.

Por tudo isto - e pelo que se ilustrará seguidamente -, não surpreende que Abel Botelho se tenha entusiasmado com a redação simultânea de uma

\footnotetext{
4 Não por acaso, também Joel Serrão (1978: 113, 115-6), ao assinalar em $O$ Livro de Alda o recurso de Abel Botelho ao tópico do "amor desenganado", também refere que o escritor procede de acordo como o "figurino camiliano"; noutro passo, o crítico defende mesmo que "naquilo de mais típico ele [Abel Botelho] foi provém da linhagem literária de Camilo", já anunciando o estilo singular de Raul Brandão.
} 
peça teatral a partir da trama de Fatal Dilema, em 1893, ainda inédita. Quer na narrativa romanesca, quer nesta sua "versão" teatral, Abel Botelho procura fugir à tipificação das personagens do universo realista, acentuando antes a sua complexa individualidade. Sem com isso abandonar completamente a importância que o ideário naturalista concedia às anomalias psicofisiológicas à luz de uma preocupação analítica, "científica" e determinista, com destaque para a influência da educação, do meio e da hereditariedade. Do que resulta frequentemente uma pintura crua, centrada nos desvios e nas taras humanas, enfim, na decadência da sociedade finissecular. ${ }^{5}$

\section{II}

Ao centrar a atenção da narrativa na interioridade das personagens, Abel Botelho acaba por cultivar os princípios naturalistas de forma pouco equitativa em Fatal Dilema, sendo frequente, por ex., observarmos a existência de momentos que escapam ao controle omnipotente e omnisciente do narrador naturalista que intenta a composição inicial da tese do romance. Um desses momentos ocorre após D. ${ }^{a}$ Isabel Penalva, num ataque de delírio, ter proposto a Heitor, seu amante, que se case com Susana, sua filha, para que deste modo ele possua em absoluto tudo o que lhe pertence:

“Perante a abjecção picante da proposta, Heitor sentia-se outro; e diante dessa miragem paradisíaca em que a libertina aberração de uma histérica lhe incendiara o desejo, um violento relâmpago lhe vergastou o íntimo, enquanto se abalavam os mais imundos recôncavos da sua alma, batidos de uma rajada dissolvente." (Botelho, 2007: 149)

5 Este procedimento de Abel Botelho não é um caso isolado. Relembre-se a prática de vários autores oitocentistas, franceses ou portugueses (de Zola a Camilo), que procederam a reescritas e adaptações teatrais de obras de ficção. 
No segmento textual transcrito, o narrador assume uma posição transcendente, revelando-se conhecedor absoluto quer dos acontecimentos externos anteriores a este momento da ação (a enunciação da "abjecção picante da proposta" de D. ${ }^{a}$ Isabel) quer do seu efeito no espaço psicológico da personagem (a proposta operara como "um violento relâmpago" que “vergastou o íntimo" de Heitor e abalara "os mais imundos recôncavos da sua alma"). No entanto, depressa, o narrador abdica da função de enunciador único e exclusivo do discurso para ceder a sua voz à da personagem:

“ [...] - Casar com Susana! Ele!?... Que barbaridade! Parecia à primeira vista uma monstruosidade, um sacrilégio... Não entraria na cabeça de qualquer. E afinal era uma coisa, sim... perfeitamente nos domínios do possível. Nem ele nem ela deviam a cabeça a ninguém... Uma infamíssima ingratidão para com a D. Isabel?... Talvez. Mas era isso da ordem natural das coisas, e em certo modo a expiação do que ela fizera ao marido. Queria lá saber! E a propósito, até nesse particular, para a pôr de bem com o mundo, este casamento lhe servia... Poria ponto a murmurações, seria o seu alvo-conduto de bom porte, não é assim?... Pois!... Continuar com as duas?... Não podia ser! E nada, com efeito, para garantir a honestidade da mãe, como o consórcio do seu presumido amante com a filha! - E num desconcertado impulso de singulares e monstruosos apetites, a cada momento Heitor voltava a pensar: - Susana! A incoercível Susana! A ele sobretudo, mais do que a ninguém, é que esta depuradora ligação convinha... Sempre algemado à paixão, sempre na rodilha do vício: estava farto. E o regaço puro e calmo dessa criança poderia ser o seu refúgio pacificador e santo ao seu declínio de vida, já nada distante... [...] Oh, a incomparável Susana!... E afinal porque não?..." (Botelho, 2007: 149-150) 
Como facilmente se observa, no extrato que transcrevemos, o narrador omnisciente, ao atribuir a sua função à personagem, através do recurso ao discurso indireto livre, permite-nos assistir à reflexão interiorizada, não pronunciada, de Heitor. As pausas sucessivas, os paralelismos de construção, as múltiplas frases exclamativas e interrogativas demonstram a perturbação interior da personagem que se autonomiza perante o narrador, na expressão de um discurso mental que patenteia o encadeamento lógico da ponderação dos argumentos a favor e/ou contra a anuência da proposta de D. ${ }^{\text {a }}$ Isabel.

O leitor tem, assim, acesso à corrente de consciência - espontânea, elíptica, sincopada e caótica - que levará esta personagem a aceitar a proposta indecorosa de D. ${ }^{a}$ Isabel Penalva de seduzir Susana. Contudo, a determinado momento desta cogitação, verifica-se que o próprio narrador omnisciente talvez sentido que já não controla plenamente o discurso, dada a sua dimensão - interrompe a enunciação da personagem ("a cada momento Heitor voltava a pensar"), assinalando, deste modo, a sua existência dentro da extensa enunciação de natureza reflexiva.

Importa, porém, salientar que a relevância das inferências deduzidas a partir dos exemplos apresentados reside na variedade e multiplicidade de discursos interiores, plenos de espontaneidade psicológica, que cunham este volume, em todos os capítulos e em sequências determinantes da ação. Sobre este propósito, observe-se ainda, a título de exemplo, os pensamentos de Susana sobre a incerteza do seu destino e do de sua mãe, após a fatalidade inesperada da morte de seu pai, Eusébio Penalva:

“- Que havia de ser dela agora? Dela e de sua mãe?... Sós as duas, sem mais ninguém amigo no mundo? Com tanta gente a quere-lhes mal, a maledicência sempre espreita, e tanta soma de coisas por que olhar e numa casa tão grande?... Era positivamente de endoidecer! Era uma sorte pior que as das feras nas selvas, ou que as pedras nos caminhos... porque estas, em suma tinham claramente marcada, e conheciam de antemão, 
a dura condição do seu destino! Antes tivesse ido ela, que não fazia falta a ninguém! - mas, ao pensar assim, logo os olhos de Susana voltavam a arrasar-se de lágrimas [...]." (Botelho, 2007: 87-88)

Neste fragmento, o narrador apoia-se nas estratégias narrativas e discursivas já descritas mas, desta vez para anunciar as motivações que incitam Susana, inocentemente, a amar Heitor, ou seja, a sujeição às restrições impostas à condição feminina de Oitocentos, que definia as mulheres como seres social e economicamente dependentes de uma figura masculina (o pai, o marido ou o amante), impelirá Susana a contemplar Heitor como o seu possível futuro marido, como o único "amigo no mundo", capaz de arrebatar mãe e filha da "dura condição do seu destino". Em suma, este monólogo interior expressa uma das razões que estará na origem de toda a trama: Heitor será objeto de desejo por parte da mãe e da filha.

Os segmentos textuais transcritos exemplificam as considerações previamente anunciadas, mas outros há de especial interesse ao longo de toda a ação romanesca: os frequentes devaneios febris e angustiantes de D. ${ }^{a}$ Isabel Penalva, ora quando esta espera o amante ora quando se vê trocada por este, em detrimento da filha; o pensamento secreto de Susana, no momento em que confessa a si mesma amar Heitor; as considerações viscerais de um Heitor enciumado que percorre as ruas da Baixa lisboeta, no encalço de Susana e Albano, numa das suas visitas caritativas.

No fundo, à medida que a ação se desenrola, são-nos gradualmente fornecidas informações sobre a vivência interior e as motivações das personagens, preparando-se, deste modo, o derradeiro conflito interior que culminará num desenlace trágico:

“Como haviam tomado corpo essas relações de escândalo? Em que condições purularam? Desde quando?... Não tinha meio de saber! Nem isso lhe importava! - Para a 
irreparável dissolução do seu anseio altíssimo, era uma coisa indiferente... Qualquer das duas hipóteses fundamentalmente lhe repugnava. Quer simplesmente actual, quer ignobilmente alimentada de longe, a nauseante aposição desses dois consanguíneos desejos ficava sendo uma barreira sem fim, cortando o imaculado voo aos seus votos, pondo termo sem recurso ao seu destino. De ora avante, para a sua consciência em alarme, e assombrando de morte a alada miragem da sua ventura, esse galanteio impudente havia de erguer-se sempre, como um dique de extermínio..., fazendo-a estalar de dor, ou sucumbir de vergonha... odiado como um monstro, ou temido como um perigo! Nunca mais deixaria de baloiçar-se implacável esse espantalho entre o seu coração e o seu instinto.

E não havia por onde sair deste dilema fatal, deste abominável círculo de inferno!" (Botelho, 2007: 332)

Eis, enfim, o "dilema fatal" que intitula a obra: a confirmação de que Heitor é o amante de sua mãe e de que este relacionamento originara a morte de seu pai impõem a Susana a vivência dilemática de amar ou odiar Heitor, de ceder ou não a sua probidade ao instinto. Esta dicotomia moral encaminhará irremediavelmente Susana até à morte, uma vez que se apresenta como fatal para uma criatura frágil e virtuosamente elevada, construída segundo o figurino romântico.

Todas estas considerações permitem-nos depreender assim que, nos momentos fulcrais da intriga e, consequentemente, da trama trágica, a tessitura da ficção escapa ao narrador objetivo e desapaixonado naturalista, visto que este prefere atribui-la às próprias personagens, ao dar voz à sua mundividência interior. A sua subjetividade e os seus conflitos interiores são a génese das conjunturas narrativas. Esta opção traduz-se, aliás, no próprio título que, desde logo, vaticina uma fatalidade desencadeada pelo "dilema" de um ou de vários dos intervenientes. 
O incumprimento do preceito realista naturalista do narrador capaz de uma observação e análise minuciosas - apartadas do sentimental e do subjetivo -, relaciona- -se com a própria extemporaneidade da obra romanesca de Botelho, dado que, na segunda metade do século XIX, assistimos ao progressivo esgotamento da fórmula realista naturalista, graças não só às conquistas científicas e mutações culturais de então - que tinham como panegírico a peculiaridade do sujeito individual -, mas também à gradual valorização da personagem como figura central do romance e do seu universo. Fatal Dilema é um exemplar denunciativo da "crise de omnisciência narrativa" e, consequentemente, da "crise do romance naturalista" que, nas palavras de Michel Raimond:

“[a conduit à une mutation] de Zola à Alain-Fournier, de Bourget à Gide, de Balzac à Proust; du récit objectif au monologue intérieur; du roman écrit par un auteur omniscient au récit disloqué où l'évènement est successivement vécu dans la conscience de chaque personnage; du roman fondé sur l'agencement d'une intrigue au roman qui s'applique à moduler des thèmes; du roman rempli de personnages idéalisés au roman qui renonce à la raideur de l'homo fictus pour rejoindre la grouillante pénombre d'une âme vivante." (Raimond, 1993: 13, 14)

Estas palavras são, de facto, elucidativas e válidas para o entendimento do uso de monólogos interiores e da preferência por uma focalização interna em Fatal Dilema, porém, cremos ainda que a presença destas técnicas narrativas se prende com uma outra circunstância, relacionada com a vertente menos estudada do percurso literário do autor.

Devido ao dilatado tempo que decorre entre a elaboração (1899) e a publicação do romance (1907), Abel Botelho termina-o com "Uma Aclaração" ao leitor, na qual refere que tal hiato se deve ao facto de "Pouco depois de 
concluído o manuscrito, seduziu-me a sugestiva exteriorização do palco, determinando-me a enquadrar o assunto numa peça." (Botelho, 2007: 365). A peça referida é Fatal Dilemmá, o drama inédito assinalado por Monique BenoîtDupuis que nele destacou um aspeto curioso: “Sa pièce n'a rien à voir avec celle du roman." (Benoît-Dupuis, 1977: 67).

Com efeito, a ação do drama não é a adaptação teatral da narrativa homónima, já que ele nos apresenta um novo conjunto de personagens que experimentam um outro enredo. Contudo, se tivermos em consideração esta constatação e o facto de que Abel Botelho se dedicou ao romance após o teatro se lhe ter revelado pouco propício (cf. Sampaio, 1931), conseguimos pressentir no volume Fatal Dilema a arte do dramaturgo.

Para o desejável entendimento desta última asserção, parece-nos pertinente referir a obra La dramaturgie classique en France, na qual Jacques Scherer sustenta que todo o conflito dramático clássico se alicerça num "debate de consciência", uma vez que as peças teatrais colocam em cena um herói que é forçado a escolher entre duas atitudes que são igualmente legítimas mas, inconciliáveis:

“Prenant conscience de cette situation, l'héros l'exprimera un raisonnement qui pèse tour à tour chacune des deux possibilités, montre que la réalisation de chacune d'elles conduit à l'inacceptable sacrifice de l'autre et qu'il est par suite incapable de réaliser aucun des deux. Un tel raisonnement est connu sous le non de dilemme." (Scherer, 1970: 67)

Assim, conclui-se que o conflito dramático clássico tem a sua origem na enunciação e experimentação de um dilema. Ora, tal como fora precedentemente demonstrado, também a ação do romance de Botelho é determinada por um ou

6 Este drama inédito constitui o corpus de uma dissertação de Mestrado em curso que visa uma análise comparativa entre o romance e o drama homónimos. Temos ainda a intenção de estudar, futuramente, as restantes peças teatrais inéditas, no âmbito de uma investigação mais alargada sobre a dramaturgia de Abel Botelho. 
vários dilemas, tendo estes tido tal preponderância na construção do romance que o autor sentiu não só o impulso de escrever uma peça teatral, como também a pretensão de demarcar a sua real importância ao integrar no próprio título da obra o termo "dilema".

Mais: se relembrarmos o primeiro extrato transcrito, verificamos que as palavras de Heitor se assemelham ao que se denomina, em teoria teatral, de monólogo de reflexão, em que a personagem, face a uma escolha delicada, "expõe a si mesma os argumentos e contra-argumentos de uma conduta" (Pavis, 1999: 248). Heitor pondera as vantagens e as desvantagens do seu casamento com Susana, chegando mesmo a considerar manter o relacionamento com a mãe desta, depois de ter casado com ela. Este é o seu dilema.

Além disso, em Susana ecoa o espírito de outras heroínas que viveram violentos dilemas em cena e que encarnaram o conflito psicológico entre o amor e o dever moral ou o amor e a razão de estado, como por exp. Antígona de Sófocles, Fedra de Racine e Jocasta, no Édipo de Corneille. Com efeito, os monólogos interiores de Susana, bem como todos os outros na narrativa, sugerem-nos os monólogos teatrais que visam a exteriorização de um "debate de consciência" (Pavis, 1999: 247) sob o qual se constrói todo conflito dramático.

Esta interferência da composição dramática no discurso narrativo e/ou a assimilação de técnicas narrativas em peças teatrais têm constituído o corpo de diversos estudos no campo da investigação literária. A título exemplificativo, a propósito desta última imiscuição, Florence Fix (Fix, 2007) identificou a presença de vários elementos narrativos na escrita didascálica do teatro de Eugène O’Neill. Segundo esta estudiosa, podemos observar nas didascálias do dramaturgo americano não só uma aplicação objetiva - no sentido em que determinam as condições concretas da enunciação e do espaço cénico, desempenhando uma função predominantemente diretiva -, mas também, uma utilização subjetiva, dado que elas fornecem esclarecimentos sobre os antecedentes da ação e o passado das personagens, uma descrição detalhada e interpretada da aparência e dos gestos das personagens, comentários sobre as verdadeiras motivações e intenções dos intervenientes. Tais explanações - que 
chegam a ser expostas em longos parágrafos ou mesmo páginas inteiras - têm o intuito de conferir um maior realismo e coerência ao enredo teatral:

“[...] O'Neill donne à ses personnages l'assise et la profondeur de personnages de roman réalistes en offrant par le biais de la didascalie des retours en arrière et des explications à leur attitude, à leur aspect ou à leurs paroles sur scène; la didascalie sert à donner cohérence au discours présent, elle lui donne motivation et justification avant la prise de parole du personnage [...]". (Fix, 2007: 144)

Fix conclui que o discurso didascálico em Eugène $\mathrm{O}^{\prime}$ Neill tem em vista colmatar as insuficiências do diálogo e gestos teatrais na construção de uma realidade, concebendo, assim, um teatro "qui veut utiliser, emprunter, certaines commodités du roman pour compléter l'architecture du drame." (Fix, 2007: 155)

Ora, se O’Neill introduz elementos narrativos na escrita didascálica, para alcançar uma maior proximidade ao real - porque o gesto e o diálogo das personagens lhe parecem insuficientes para tal -, no romance Fatal Dilema, Abel Botelho recorre a situações dilemáticas teatrais, para elaborar uma intriga narrativa centrada nos desejos e nos pensamentos mais íntimos das personagens, pois, ao tornar enunciativo (exterior), todo um discurso íntimo (interior), o romancista deparou-se com as restrições da criação naturalista que organizava a trama segundo fatores e acontecimentos externos às personagens. No fundo, tanto Eugène O'Neill como Botelho resolveram as fragilidades dos géneros por si praticados, com recurso a técnicas de um outro género.

Com efeito, como dramaturgo, Abel Botelho intuiu que a ação do quarto volume de Patologia Social vivia do ponto de vista dilemático das personagens da ficção, daí, "a sugestiva exteriorização do palco" e a sua determinação para "enquadrar o assunto numa peça", dado que toda a narrativa é estruturada segundo conflitos interiores, tal como fora praticado na tragédia clássica grega o ágon -, ou no teatro clássico, com o princípio agonístico dos carateres da ação. 
Enquanto leitores de Fatal Dilema, sentimo-nos frequentemente parceiros, cúmplices da "corrente de consciência" das personagens, tal como nos sentimos parceiros discursivos do monologante, enquanto espectadores de um monólogo teatral. O leitor de Fatal Dilema é reiteradamente colocado como voyeurs das personagens.

A peça não chegara a ser representada, face ao "intransigente horror" ou à "precavida esquivança de várias empresas teatrais", e o escritor voltara "então à primeira forma do romance, a mais completa aliás e a mais liberta do convencional travão de preconcebidas fórmulas" (Botelho, 2007: 365). Esta última asserção do romancista não deve ser descurada, pois: por um lado, ela testemunha o receio e a resistência das empresas teatrais de Oitocentos em assumirem o papel de dinamizadores da desejada renovação teatral naturalista, uma vez que a manutenção e a continuidade das companhias teatrais dependiam do sustento do gosto do público; por outro lado, ela indicia que Abel Botelho pressentira o romance já como um cosmos passível de albergar personagens de uma complexa individualidade, por sua vez, capaz de fomentar um (novo) universo romanesco, liberto do "convencional travão de preconcebidas fórmulas", no fundo, livre das limitações da fórmula de composição da narrativa romanesca realista naturalista. Com Fatal Dilema, de facto, Botelho encontrara no romance a forma de expressão ideal para uma narrativa intrinsecamente teatral.

Em suma, por todas considerações precedentemente apresentadas, julgamos que um conhecimento mais aprofundado de Fatal Dilema - e até dos restantes volumes que formam o ciclo Patologia Social - passa pelo entendimento de que a sua narrativa é indissociável de uma "teatralidade interna". Mais: pensamos ainda que o estudo da dramaturgia de Abel Botelho poderá vir a esclarecer a arte narrativa daquele que haveria de permanecer sempre refém de uma aprendizagem naturalista e de um "temperamento de feição romântica" (Serrão, 1978: p.112). 


\section{Referências bibliográficas:}

BENOÎT-DUPUIS, Monique. “Contribution à la bibliographie d'Abel Acácio de Almeida Botelho". In: separata de Sillages, n. ${ }^{0}$ 5, pp. 49-73, 1977.

BOTELHO, Abel. Pathologia Social: O Barão de Lavos, 2. ${ }^{a}$ ed., vol. 1. Porto: Chardron, 1898 [corrig.; 1. ${ }^{\text {a }}$ ed. 1891].

- . Fatal Dilema. Baguim do Monte: Lello Editores, 2007 (Col. «Obras de Referência»; edição patrocinada pela Câmara Municipal de Tabuaço).

FIX, Florence. "L'écriture didascalique chez O'Neill”. In: FIX, Florence e Frédérique Toudoire-Surlapierre, La didascalie au XXe Siècle: regarder l'impossible. Dijon: Ed. de 1'Université de Dijon, 2007 , pp. 143-155.

JESUS, Maria Saraiva de. "Botelho (Abel Acácio de Almeida)". In: Biblos, Enciclopédia Verbo das Literaturas de Lingua Portuguesa, vol. 1. Lisboa/São Paulo: Ed. Verbo, 1995, pp. 721-724.

PAVIS, Patrice. Dicionário de Teatro. (trad. portuguesa sob direção de J. Guinsburg e Maria Lúcia Pereira). São Paulo: Editora Perspectiva, 1999.

PINTO, Júlio Lourenço. Estética Naturalista (Estudos Críticos). Lisboa: IN-CM, 1996 [1884].

RAIMOND, Michel. La crise du roman, des lendemains du Naturalisme aux années

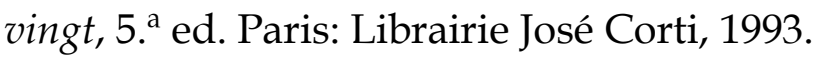

SAMPAIO, Albino Forjaz de. Abel Botelho, a sua vida e a sua obra. Lisboa: Empreza do Diário de Notícias, 1931. Col. «Colecção Patrícia».

SCHERER, Jacques. La dramaturgie classique en France. Paris: A.G. Nizet Editeur, 1970.

SERRÃO, Joel. “Apontamentos sobre os romances de Júlio Lourenço Pinto e de Abel Botelho". In: Temas Oitocentistas. Lisboa: Livros Horizonte, 1978, pp. 111116.

SIMÕES, João Gaspar. "Abel Botelho". In: Perspectiva Histórica da Ficção Portuguesa das origens ao século XX, 2. ${ }^{\text {a }}$ ed.. Lisboa: Dom Quixote, 1987. 